\title{
Characterization of poly(ethylene terephthalate) used in commercial bottled water
}

\author{
Cristina Bach $^{1,2}$, Xavier Dauchy ${ }^{1}$, Serge Etienne ${ }^{2}$ \\ ${ }^{1}$ Laboratoire d'Etudes et de Recherches en Hydrologie (LERH)-Agence Française de \\ Sécurité Sanitaire des Aliments (AFSSA), 40 rue Lionnois, F54000 Nancy France \\ ${ }^{2}$ Nancy Université, Institut Jean Lamour, UMR 7198 CNRS, Dpt SI2M - Parc de \\ Saurupt - CS 14234, F54042 Nancy Cedex France \\ c.bach@afssa.fr
}

\begin{abstract}
The aim of this study is to determine which compounds are present into drinking water packaged in poly(ethylene terephtalate) bottles and to know the origin of these substances in relationship with the material.

A screening procedure was established for the detection of unknown compounds into bottled water. A panel of water bottles has been tested after exposure to extreme conditions of temperature and UV radiation to accelerate the possible migration of substances.

At the same time, physico-chemical characterization of polymeric material has been performed namely calorimetric analysis, IRTF and low-frequency mechanical spectroscopy. The results thus obtained allow understanding in a better way the migration kinetics of molecules inside the polymer, it means the pollution of the bottled water.
\end{abstract}

\section{Introduction}

Poly(ethylene terephthalate) (PET E) is a polyester used in a wide number of applications. Its chemical inertness and physical properties made it particularly suitable in food packaging applications especially in beverages and drinking water [1]. Indeed, PET E packaging combines adequate gas barrier properties for the retention of carbonation with a glass like transparency, light weight and good recyclability.

The most common process to produce PET E involves the polycondensation of dimethyl terephthalate and ethylene glycol with antimony (Sb), germanium or titanium based catalyst [2]. Sb catalysts are used in $90 \%$ of the worldwide production of PET E [3]. Several studies have shown the presence of compounds not expected a priori in bottled water, sometimes in non negligible concentrations. Acetaldehyde, a thermal degradation compound formed during the polymerization reaction and the hot step process in the bottle water manufacture, has widely been reported in PET E packaged water [4]. Formaldehyde and acetone have also been detected in some cases [4, 5]. Sb in commercial PET E bottled water was found after the exposure to different conditions of temperature, storage and sunlight $[3,6]$. Substances relative to additives used in the plastic material processing have been reported $[7,8]$ in water packaged in PET E.

The origin of several substances is not clearly established and remains controversy. One of the possible sources is the diffusion of constituents from PET E to water, namely (i) monomer, (ii) 
catalyst, (iii) additives or degradation products formed in the manufactures or a long storage of the bottle, (iv) the impurities contained in the starting substances or additives [9] and ( $v$ ) the polyethylene (or polypropylene) caps of water bottles.

\section{Aim of the work}

The aim of our study is twofold: on one hand to study the effect of physical properties of the packaging material (caps and bottles) on the presence of substances from it to water. Such a physical characterization was performed to determine crystallinity ratio, the glass transition temperature $(\mathrm{Tg})$, the vibrational spectrum of PET E assessed by IR spectroscopy and the nature of bottles caps, generally polyethylene (PEHD) or polypropylene (i-PP).

On the other hand, a screening analytical method was designed to identify unknown compounds in water. In order to accelerate the diffusion of compounds, a panel of commercial water bottles was subjected for 15 days at $65^{\circ} \mathrm{C}$ (equivalent to an exposure between $300<t<700$ days [10]) and UV radiation dose of 9 hours $\left(1.7 \mathrm{~W} / \mathrm{cm}^{2}\right)$.

\section{Materials and techniques.}

The techniques employed for chemical and morphological characterization are presented.

\subsection{Sampling}

Some brands of French market PET E plastic drinking water was purchased in a local shop. The bottle water panel was selected according to visual parameters like bottle color, volume, thickness of plastic material and type of water like non-carbonated or carbonated water. Some PET E bottles containing carbonated water are of the multilayer type: a functional barrier (usually PA-6) is placed between two PET E layers. In this case, only the PET E in contact with water was tested.

\subsection{Water analysis}

\subsubsection{Screening method for water samples}

The accelerated conditions test was carried out in a steamroom APT.line ${ }^{\mathrm{TM}}$ KBF-ICH (BINDER, Germany). Several water extraction methods were performed to extract a large number of substances from water. Dichloromethane was used for the liquid-liquid extraction (LLE) and the elution of solidphase extraction (SPE) cartridges (Oasis HLB, Waters) was carried out in ethyl acetate. Analyses were run on a Varian 450-GC Gas Chromatograph connected to Varian 240-MS Ion-Trap Mass Spectrometer. The GC-MS was equipped with an autosampler COMBIPAL (CTC Analytics AG, Switzerland). The separation column was a Restek Rxi5MS capillary column, $30 \mathrm{~m} \times 0.25 \mathrm{~mm}$ i.d., $0.25 \mu \mathrm{m}$ film thickness. A IP deactivated guard column Restek $5 \mathrm{~m} \times 0.53 \mathrm{~mm}$ was placed before the separation column. Extracts of water samples were analyzed in the full scan mode and the mass spectral were identified by comparison with a conventional NIST MS Library Search (The National Institute of Standards and Technology Mass Spectral Library, version 2.0).

\subsection{PET E bottles}

\subsubsection{IRTF spectroscopy}

IRTF spectroscopy was carried out in order to determine the nature of polymer material and its structural state. Spectra were performed on a Nicolet 460 Spectrometer E.S.P. Each spectrum was obtained with a resolution of $4 \mathrm{~cm}^{-1}$. Sample preparation (few $\mu \mathrm{m}$ thick) was achieved by mechanical polishing of PET E cuts of stretched parts of the water bottle.

\subsubsection{Differential scanning calorimetry (DSC)}


The crystallinity ratio and the glass transition temperature of PET E samples were assessed via calorimetric measurements using a Setaram DSC-131 instrument. Specimens (few mg) were heated from $20^{\circ} \mathrm{C}$ to $350^{\circ} \mathrm{C}$ at $10^{\circ} \mathrm{K} / \mathrm{min}$. The crystallinity ratio was determined according to, $\left(\Delta H_{\mathrm{f}}-\Delta H_{\mathrm{c}}\right) /\left(\Delta H_{\mathrm{f}}^{0}\right)$, where: $\Delta H_{\mathrm{c}}, \Delta H_{\mathrm{f}}$ are the heats of crystallization and of melting of the specimen, respectively. $\Delta H_{\mathrm{f}}^{0}$ is the melting heat of the PET E ideal crystal: $140 \mathrm{~J} / \mathrm{g}$ [11]

\section{Results and discussion}

The IR spectra exhibited PET E commercial bottle is displayed in Fig. 1.

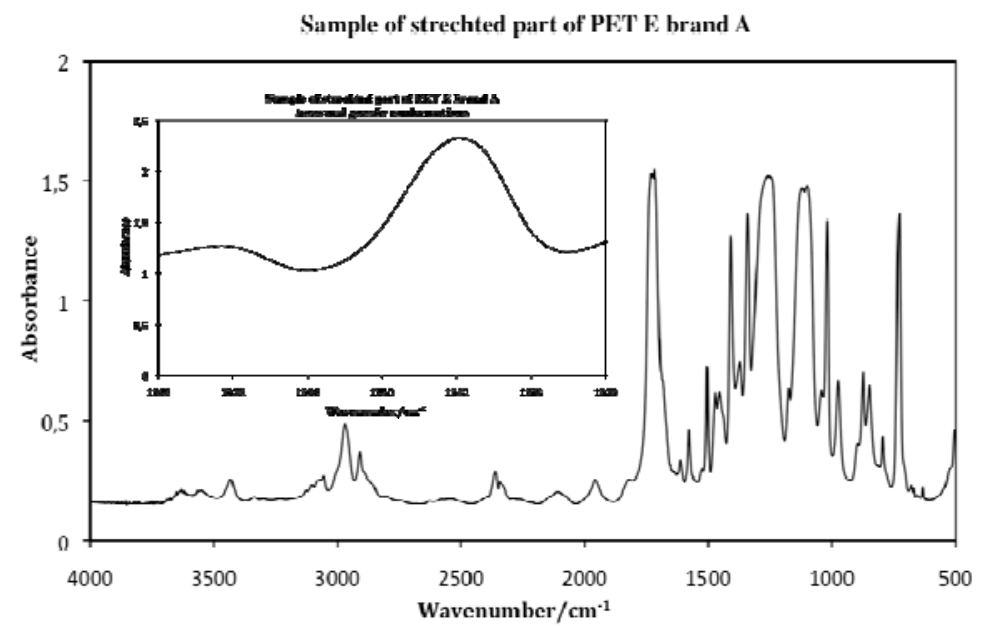

Figure 1.Infrared spectrum of the stretched part of a PET E bottle. The characteristic bands at $1340 \mathrm{~cm}^{-1}$ and $1370 \mathrm{~cm}^{-1}$ are shown in the insert.

Chemical additives present as traces and related to polymer or bottle manufacture are not observed. But these traces and degradation products could migrate from bottle to water. Thus, analytical methods allowing the detection of these substances into water with low detection limits (down to $\mu \mathrm{g} / \mathrm{l}$ ) were developed. To yield this goal, a screening analytical method was designed and the separation and identification of these compounds is in progress.

Nevertheless, the characteristic bands at $1340 \mathrm{~cm}^{-1}$ and at $1370 \mathrm{~cm}^{-1}$ are clearly observed. These bands correspond to the wagging mode of ethylene units in trans conformations and gauche conformations respectively [12]. The trans form is made more favorable by crystallization and stretching, while the gauche conformations are characteristic of the amorphous state [13].

Results of DSC measurements are displayed in Fig. 2. It is shown that the bottle neck was practically amorphous with a crystallinity ratio not exceeding $14 \%$ and a glass transition temperature $\mathrm{Tg}$ of $72^{\circ} \mathrm{C} \mathrm{e.g.} \mathrm{typical} \mathrm{value} \mathrm{of} \mathrm{PET} \mathrm{E} \mathrm{[14].} \mathrm{In} \mathrm{addition,} \mathrm{the} \mathrm{absence} \mathrm{of} \mathrm{the} \mathrm{exothermic} \mathrm{peak} \mathrm{on}$ heating confirms the crystallization of PET E in the stretched part of the bottle due to the blowing process. As an example, Table 1 shows the crystallinity ratios found in two brands of commercials bottles in PET E. Also, it is obvious that this technique is not sensitive enough to determine the $\mathrm{Tg}$ of the semicrystalline part of the bottle. Low frequency mechanical spectroscopy (LFMS) experiments are in progress to determine this value which is $10^{\circ} \mathrm{C}$ higher in semicrystalline PET E comparing to the amorphous state. First results (not shown here), indicate that a structural relaxation appears near $40^{\circ} \mathrm{C}$ with a module shear decrease about $20 \%$. This effect is not present on the second heating run. The $\mathrm{Tg}$ at $88^{\circ} \mathrm{C}$ is clearly revealed with a drastic module shear decrease. LFMS is a very sensitive method to characterize the dynamics of molecular motions in the polymer. This point is particularly attractive because these motions are suspected to make the molecule diffusion faster in the polymer.

The nature of the caps for two brands of bottles is also shown in Table 1. The identification was possible due to a large difference of the melting points of PEHD and i-PP: $120-130^{\circ} \mathrm{C}$ and $150-175^{\circ} \mathrm{C}$, 
respectively [15]. Results revealed that the nature of caps depends on the type of water stored in the bottle.

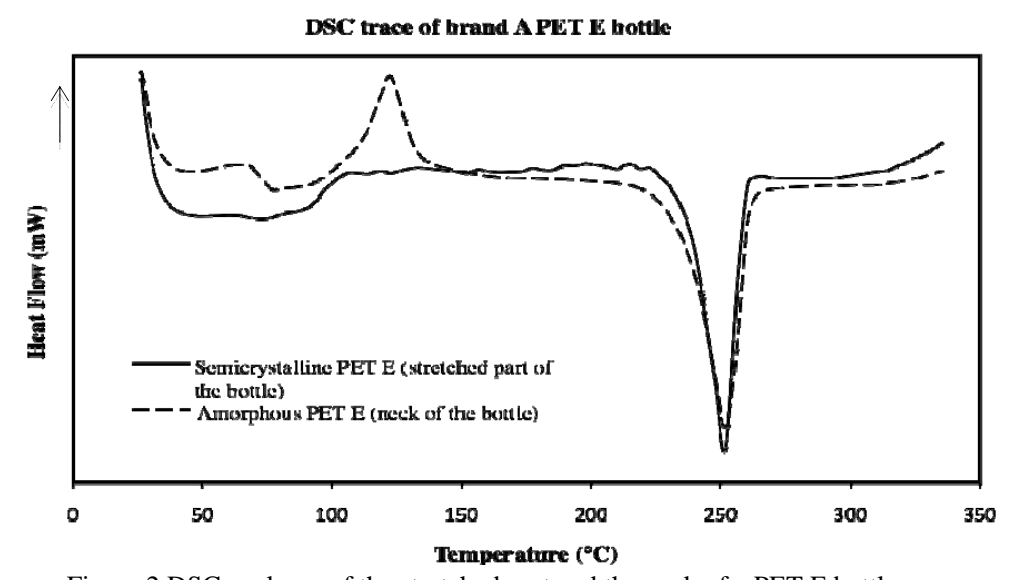

Figure 2.DSC analyses of the stretched part and the neck of a PET E bottle.

Table 1.Crystallinity ratio and nature of caps in two commercial PET E water bottles.

\begin{tabular}{|c|c|c|c|c|}
\hline $\begin{array}{c}\text { Water } \\
\text { Bottles }\end{array}$ & Type of water & Bottle Layers & $\begin{array}{c}\text { Crystallinity ratio } \\
\text { (stretched zone) }\end{array}$ & $\begin{array}{c}\text { Nature of caps } \\
\text { (melting température) }\end{array}$ \\
\hline Brand A & $\begin{array}{c}\text { Carbonated } \\
\text { mineral water }\end{array}$ & PET E-PA-PET E & $31 \%$ & $\begin{array}{c}\text { i-PP } \\
\left(174^{\circ} \mathrm{C}\right)\end{array}$ \\
\hline Brand B & $\begin{array}{c}\text { Non-carbonated } \\
\text { water }\end{array}$ & PET E & $21 \%$ & $\begin{array}{c}\text { PEHD } \\
\left(125^{\circ} \mathrm{C}\right)\end{array}$ \\
\hline
\end{tabular}

\section{Conclusions and Perspectives}

The physical characterization of PET E in commercial bottles of drinking water is important to explain the interaction of packaging with water. The blowing process during the bottle manufacture induces the polymer crystallization by stretching. DSC measurements shown the crystallization ratios between 20 to $30 \%$ in the stretched part of the bottle tested, but are not able to reveal the orientation of these crystals. The X-ray scattering (SAXS and WAXS) will be carried out to characterize more in detail the structure and arrangement of PET E polymeric chains in the bottle.

Using the screening method in bottled subjected to extreme conditions, several substances relative to additives have been found in water. The confirmation of their presence and quantification of these substances is in progress. Also, it is necessary to determine the relative roles of the bottle (PET E) or caps (PEHD or i-PP).

\section{References}

[1] Packaging Materials. 1. Polyethylene terephthalate (PET) for food packaging applications. Report Series. International Life Sciences Institute (ILSI), 2002.

[2] Stoyko Fakirov; Handbook of thermoplastic polyesters. Vol.1, Wiley-VCH, Weinheim, 2002.

[3] Westerhoff, P., Prapaipong, P., Shock, E. and Hillaireau, A., 2008, Antimony leaching from polyethylene terephthalate (PET) plastic used for bottled drinking water. Water Research, 42, 551-556.

[4] Mutsuga M., Kawamura, Y., Sugita-Konishi, Y., Hara-Kudo, Y., Takatori, K., and Tanamoto, K., 2006, Migration of formaldehyde and acetaldehyde into mineral water in polyethylene terephthalate (PET) bottles. Food Additives and Contaminants, 23(2): 212-218.

[5] Nawrochi, J., Dabrowska, A. and Borcz, A., 2002, Investigation of carbonyl compounds in bottled waters from Poland. Water Research, 36, 4893-4901.

[6] Keresztes, S., Tatar, E., Mihucz, V. G., Virag, I., Majdik, C. and Zaray, G., 2009, Leaching of 
antimony from polyethylene terephthalate (PET) bottles into mineral water. Science of the Total Environment, (article in press).

[7] Cao, X., 2008, Determination of phthalates and adipate in bottled water by headspace solidphase microextraction and gas chromatography/mass spectrometry. Journal of Chromatography A, 1178, 231-238.

[8] Toyo'oka, T. and Oshige Y., 2000, Determination of alkylphenols in mineral water contained in PET bottles by liquid chromatography with coulometric detection. Analytical Sciences, 16, 1071-1076.

[9] Muncke, J., 2009. Exposure to endocrine disrupting compounds via food chain: Is packaging a relevant source? Science of Total Environment, (article in press).

[10] Feigenbaum, A., Dole, P., Aucejo, S., Dainello, D., De La Cruz Garcia, C., Hankemeier, T., N’Gono, Y., Papaspyrides, C. D., Paseiro, P., Pastorelli, S., Pavlidou, S., Pennarun, P. Y., Saillard, P., Vidal, L., Vitrac, O. and Voulzatis, Y., 2005. Functional barriers: properties and evolution, 22(10), 956-967.

[11] Liangbin, L., Rui, H., Ai, L., Fude N., Shiming, H., Chunmei W., Yuemao, Z. and Dong, W., 2000. High pressure crystallized poly(ethylene terephthalate): high crystallinity and large extended-chain crystals. Polymer, 41, 6943-6947.

[12] Duchesne, C., Kong, X., Brisson, J., Pézolet, M. and Prud'homme, R. E., 2002. Molecular orientation and relaxation of poly(ethylene terephthalate) by polarization modulation infrared spectroscopy. Macromolecules, 35, 8769-8773.

[13] Atkinson, J. R., Biddlestone, F. and Hay, J. N., 2000. An investigation of glass formation and physical ageing in poly(ethylene terephthalate) by FT-IR spectroscopy. Polymer, 41, 69656968.

[14] Etienne, S. and David, L. Introduction à la science physique des polymères. Dunod, Paris, 2002.

[15] Wunderlich B., 1980. Macromolecular physics vol. 3. Academic Press, New York 